\title{
Proceeding
}

Supplementary Issue: Summer Conferences of Sports Science. Costa Blanca Sports Science Events, 25-26 September 2020. Alicante, Spain.

\section{Proprioceptive training and sports performance}

\author{
ARIO FEDERICI $\triangleleft$, FEDERICO ZUMBO, FRANCESCO LUCERTINI, CARLO FERRI MARINI \\ Department of Biomolecular Sciences, University of Urbino "Carlo Bo", Italy
}

\begin{abstract}
One of the current trends in the field of sports training concerns the integration into training programs of exercises defined as "proprioceptive", which also include balance exercises, used to optimize performance, prevention or recovery from injuries. After introducing and describing the main characteristics of proprioceptive training in sports, the present review aims to set out and analyse the various flaws in this type of training as it is commonly practiced, in order to lay the groundwork for future improvements in proprioceptive training. Our research highlights that it is common practice to combine proprioceptive training with training on unstable surfaces, generally meaning the same for both situations. Such practices are indicative of the confusion surrounding the concepts of proprioception and balance. Indeed, until these two concepts and their respective performance benefits are clearly differentiated, it will be difficult to move beyond the controversy surrounding proprioceptive training and hence. to make advances in the field of proprioceptive training research. In conclusion, therefore, against the comforting theories that accompany the use of proprioceptive training in relation to the improvement of performance, unfortunately there is a literature that shows many variables not yet considered or treated in an approximate way.
\end{abstract}

Keywords: Proprioceptive training; Performance; Balance; Feet.

Cite this article as:

Federici, A., Zumbo, F., Lucertini, F., \& Marini, C.F. (2020). Proprioceptive training and sports performance. Journal of Human Sport and Exercise, 15(4proc), S1160-S1168. doi:https://doi.org/10.14198/ihse.2020.15.Proc4.17

Corresponding author. Department of Biomolecular Sciences, University of Urbino "Carlo Bo", Italy.

E-mail: ario.federici@uniurb.it

Abstract submitted to: Spring Conferences of Sports Science. Costa Blanca Sports Science Events, 19-20 June 2020. Alicante, Spain.

JOURNAL OF HUMAN SPORT \& EXERCISE ISSN 1988-5202

(c) Faculty of Education. University of Alicante

doi:10.14198/jhse.2020.15.Proc4.17

S1160 | 2020| Proc4 | VOLUME 15

(C) 2020 University of Alicante 


\section{INTRODUCTION}

Until recently, proprioceptive training was used almost exclusively in post-trauma rehabilitation, specifically, to reactivate the functionality of muscle and joint receptors. However, even in healthy individuals, it has been shown that increasing the quality of reception using the proprioceptive system leads to tangible improvements in terms of the rapidity and precision of the the central nervous system response. It can therefore be deduced that proprioceptive training may also be able to enhance athletic performance. Specifically, the proprioception of the foot-ankle complex seems to play a particularly important role in athletic performance, as the anklefoot complex is often the only part of the body in contact with the ground (Han, 2014; Han, 2015).

Han (2015), in fact, found that good ankle-foot proprioception is positively correlated, for example, with performance levels in football. He believes that experienced footballers share less core capacity to process proprioceptive information for motion control, and thus they are able to pay more attention to tasks such as locating teammates and opponents, determining the best opportunity to pass the ball or kick.

Proprioceptive control is fundamental, not only for sports characterized by situational variables such as football, but also in the execution of any complex motor activity such as pedalling a bicycle. The cyclist must not only be able to maintain balance on the bicycle but must also be able to "feel" and modulate the activity of each area of the body. In other words, developing a correct pedalling technique, i.e. having a good "pedal stroke", can only be achieved by making use of the sensations that the proprioceptive system makes available to the organism. Even for disciplines such as figure skating, in which a great sense of balance and absolute control of technical movements is essential, proprioceptive sensitivity is essential.

In sport today, this type of proprioceptive sensitivity is trained, almost exclusively, through exercises that employ simple common tools found in all gyms and rehabilitation centres, namely tilting boards, axes, bouncers, shimmies or BOSU.

The enhancement of athletic performance, undoubtedly, represents the cutting edge of the use of proprioception, and as such, it is characterized by flaws and controversies that still need to be analysed and explored scientifically.

\section{PROPRIOCEPTIVE TRAINING AND THE DEVELOPMENT OF VARIOUS MOTOR SKILLS AND MOTOR CAPACITIES}

In healthy people, the positive effects of this kind of proprioceptive training, usually carried out on unstable surfaces, mainly consist in improvements in the subject's ability to maintain balance, i.e. in the reduction of postural oscillations (Hoffman \& Payne, 1995), both in adults (Gioftsidou et al., 2006; Yaggie \& Campbell, 2006; Granacher et al., 2010; Romero-Franco et al., 2012), and in children (Dobrijevic et al., 2016).

Regarding strength, however, there is a general consensus that the application of proprioceptive training has no effect on this motor capacity, but that it positively affects the rate of force development (RFD) (Gruber \& Gollhofer, 2004; Granacher et al., 2010). This suggests that improvements in proprioception may have a positive impact on the neural-arousal activation of the motor-neural system, in particular, as regards the stretch shortening cycle (SSC) (Komi, 1984; Gruber \& Gollhofer, 2004). On the other hand, there are divergent and often conflicting findings regarding the effect of proprioceptive training on explosive strength and agility (Yaggie \& Campbell, 2006; Cressey et al., 2007; Šimek et al., 2008; Granacher et al., al., 2010). 


\section{Anatomo-physiological bases in the vertical jump}

Considering the importance of the vertical jump as a predictor of muscle power and the role it plays in sports, several studies have investigated the effects of proprioceptive training on jumping ability (Ziegler et al., 2002; Kovacs et al., 2004).

The vertical jump is a complex multi-joint activity that requires great muscle strength in the hip, knee and ankle joints (Lees et al., 2004). Previous research has shown that proprioceptive training enhances the strength of the flexor and extensor muscles of the foot (Tropp \& Askling, 1988) as well as the strength of the posterior thigh muscles (Heitkamp et al., 2001). The ability of proprioceptive training to increase leg extensor muscle strength together with its capacity to inhibit the stretch reflex (Lloyd, 2001) and co-contraction mechanism, may also account for possible improvements in vertical jump performance. Considering that explosive force generation in vertical jumping is affected by the rapid transfer from eccentric to concentric muscle work, it is possible that proprioceptive training has an effect on rapid force generation and may increase frequency and early recruitment of motor units (Gruber \& Golhoffer, 2004), thus leading to an increase in the height of vertical jumps. In addition, the contribution of the muscle activity in the hip joint is also very important in maximal vertical jumping performance and very often determines the height of the jump, thus differentiating between submaximal and maximal jumping performance (Lees et al., 2004).

Although Ziegler (2002) noted large changes (12\%) in the height of the countermovement jump (CMJ), her investigation was conducted on an untrained female population. In Yaggie and Campbell's (2006) study on physically active subjects, no significant changes in vertical jump performance were found after a balance training program based on a balance half ball. Bruhn, Kullmann, and Gollhofer (2004) also studied the effects of proprioceptive training on height change in the squat jump (SJ). After four weeks of training on unstable surfaces, no significant change in jump height was found, although a numerical difference was noted.

A very interesting study was conducted by Gaurav et al. in 2013. The aim of the investigation was to compare the effectiveness of conventional proprioceptive training (wobble board) with multi-station proprioceptive training on the execution of the vertical jump in basketball players. The results showed that multi-station proprioceptive training is more effective in improving vertical jumping ability in basketball players. Conventional proprioceptive training is meant to develop muscle strength, whereas multi-station training aims to enhance coordination as well as strength.

Ya-Wen Liu et al., (2005) proposed that multi-station training involves multiple muscles and further confirmed that proprioception is governed by central and peripheral mechanisms that originate mainly from the muscle receptor, but also include tendon, articular and cutaneous receptors. Eric and Rosenbaum (2001) also conducted a study in which they used multi-station training on 12 different surfaces. They found improvements in the sense of joint position, limited postural swing, and a stable base, which helped the subjects to jump higher. They also concluded that multi-station training reduces reaction times, thus helping to release strength and jump higher at the same time.

Hence, these findings regarding the effects of proprioceptive training on various physiological aspects of our body, suggest that it can be a useful addition to standard plyometric training to enhance the explosive strength of the jump; however, further investigations are needed to confirm these results. 


\section{PROPRIOCEPTIVE TRAINING IN VARIOUS SPORTS}

The role of proprioceptive training in sports has been explored in a number of different studies conducted across a range of sports.

In a study on basketball players, Sevreza \& Bourdin (2015) found that success in free throws is determined, at least in part, by the ability of players to sense the position of distal joints based on proprioceptive impulses. In a study on junior tennis players, Westin et al., (2015) found that after applying a six-week neuromuscular and performance program, improvements were found in the players' speed, agility, dynamic balance and muscle endurance of the pelvic area. Furthermore, a study by Gombos et al. (2016) showed that proprioceptive training had beneficial effects on the athletic performance of junior handball players during official matches.

\section{Proprioceptive training in sprinters}

Speed in athletics is particularly affected by the amplitude and frequency of all body movements (Cometti, 2002). To improve both of these parameters, training must include muscle contractions at maximum intensity, correct biomechanical movements and good stability to focus and maximize strength in the movements (Cosio-Lima et al., 2003; Lin et al., 2007). Regarding the stability factor, it has been shown that under unstable conditions, strength is greatly reduced (Marshall \& Murphy, 2006) because accurate and precise contraction requires that the nervous system receive adequate position information from receptors in the muscles, ligaments, joints and skin (Behm et al., 2002 \& 2003).

Moreover, athletes who suffer from continuous fatigue and disorders that alter the proprioceptive system by sending distorted proprioceptive information, have been shown to undergo biomechanical alterations and to lose efficiency in movement (Yasuda et al., 1999). Other authors agree that during running, the neuromuscular spindle is the proprioceptive receptor responsible for performing movement, and maintaining posture and muscle tone (Fitzpatrick et al., 1994; Ganong, 2004). It is therefore the only receptor that can be modified by the central nervous system through proprioceptive training (Ashton-Miller et al., 2001). Indeed, thanks to proprioceptive training and the consequent modification of neuromuscular spindles as the main proprioceptive receptors, improvements in the strength of athletes at the start of an isometric action have been found (Gruber \& Gollhofer, 2004). Furthermore, biomechanical performance has been shown to be perfected in movements similar to those performed in proprioceptive training (Ashton-Miller et al., 2001; González et al., 2011), and an increase in muscle recruitment has been obtained during contractile activity in exercises on an unstable platform (Behm et al., 2002, 2003; Marshall \& Murphy, 2005; Anderson \& Behm, 2005). However, the overall electromyographic activity remains unchanged because the limb musculature is called upon to help maintain joint stability with instability (Anderson \& Behm, 2004; Behm et al., 2005; Kornecki \& Zschorlich, 1994).

The addition of proprioceptive exercises to athletic training, as previously observed, has led to major improvements in training programs, as reflected in improvements in subjects' reaction times and specific muscle strength, as well as greater stability and injury prevention (Gruber \& Gollhofer, 2004; Yaggie \& Campbell, 2006; Laudner \& Koschnitzky, 2010). However, there are still many aspects of proprioceptive training that need to be adapted, such as the type, volume and intensity of the exercises.

Romero-Franco et al., (2017) investigated the effect of six weeks of proprioceptive training on sprinters' balance, strength and speed. The six-week training program included 30 minutes a day of proprioceptive training using BOSU and a swiss ball. Before and after the training program, stabilometry tests were 
performed for the horizontal $(X)$ and vertical ( $Y$ planes, as well as squat jump, countermovement jump and a 30 meter sprint. The results showed that the exercise program enhanced postural balance and led to moderate increases in jump power but had no impact on speed.

On the other hand, Yaggie \& Campbell (2006) demonstrated that a proprioceptive training program improved athletes' reaction ability, which is considered a key parameter for the 30 meters speed race. An improvement in this parameter should also have been found in the previous study.

Therefore, future studies should focus on a range of variables, such as the length of the training period, as well as the inclusion of athletes of different levels and age groups. Lastly, but no less importantly, it would also be useful to investigate a wider or different range of exercises for sprinters in future research.

\section{UST (UNSTABLE SURFACE TRAINING) AND PROPRIOCEPTIVE TRAINING}

All of the studies examined thus far used tools that produce instability, such as the BOSU, the swiss ball or the wobble board, in order to enhance performance. As mentioned above, it can therefore be observed that in common practice, there is a tendency to mistakenly mix proprioceptive training with training on unstable surfaces, often willingly attributing the same meaning to both training contexts. Indeed, some advocates of training on unstable surfaces claim that such training will improve performance by improving balance, kinaesthetic sense, proprioception and strength (Brooks \& Brooks, 2002; Ruiz \& Richardson, 2005). However, the integration of unstable surface training (UST) into a neuromuscular recruitment model for a given activity (e.g. throwing on an unstable surface) can actually negatively affect the chronic performance of that ability (Willardson, 2004). Furthermore, force production under stable conditions is significantly greater than under unstable conditions, and the antagonist activity is significantly higher with instability (Behm et al., 2002).

Behm et al. (2002) attributed this altered recruitment to excess stress associated with increased postural demands (muscles that stabilize joints rather than promote movement) and dispersion of concentration (neural impulse) in an attempt to control two limbs with different responsibilities (balance and strength).

Indeed, the main finding of a study by Cressey et al. (2007) was that ten weeks of UST of the lower body attenuated jump performance improvements, and 40 yard sprint speed compared to a stable surface program identical in terms of all the other programming variables. In a broad sense, the different effects of the training programs are likely related to the fact that UST undermines the principle of specificity of training.

It is important to distinguish between instability in the foot, which is accustomed to stable surfaces in the closed chain movement, and instability in the torso and arms, which often encounter instability while the base is stable.

Indeed, most athletic movements occur when the subject is standing upright on a stable surface and the instability is applied higher in the kinetic chain. In this regard, UST turns out to be a very non-specific type of training and may be more useful when the aim is to train the core and upper body muscles. Furthermore, most athletic movements are performed at high speeds and are highly dependent on the stretch-shortening cycle (SSC). Given that UST delays the cushioning phase of the movements of the SSC, it can be deduced that the subsequent production of force due to the release of energy stored by the eccentric preload would be significantly impaired on these training surfaces (Komi, 2003). Furthermore, both the maximum force and power are affected by the SSC, the function of which appears to be negatively affected by the UST. 
Antagonistic activity is intensified during UST to maintain joint stability (Behm et al., 2002); hence, it is not unreasonable to hypothesize that such training could be detrimental to speed and optimal force production when applied for a long period of training. Therefore, although increased antagonist activation can help maintain joint stability, it can be counterproductive in terms of strength and power.

While there may be some sports (e.g. surfing or snowboarding) for which UST can offer appreciable performance gains, in light of our previous observations, it would appear that for most athletes, instability should only be applied to training for very specific contexts within a given sport. Therefore, coaches who apply UST seeking to obtain a proprioceptive training effect, may in fact compromise the development of important athletic abilities. Indeed, our findings suggest that proprioception is probably best used in specific contexts on a stable surface.

\section{DISCUSSION AND CONCLUSIONS}

Based on our findings, it is essential to underline that, without fully understanding the concept of proprioception and balance, it is difficult to understand the controversy surrounding proprioceptive training. It appears that misconceptions about proprioceptive training began to spread when it was adopted at commercial at private gyms. For example, many personal trainers and strength conditioning coaches refer to single-leg balance training on a foam pad as proprioceptive training. However, single-leg balance training is clearly not the most representative form of proprioceptive training (Sjolander \& Johansson, 1997). One of the many aspects overlooked in the literature concerns the importance of the foot and its functions. Undoubtedly, the foot plays a role of primary importance in sport, as it is the element that keeps us in contact with the ground and through which we discharge and receive force.

Therefore, at least from a scientific point of view, we have not yet focused on results that can be achieved through proper proprioceptive training in terms of improving sports performance. Indeed, more valid and logical approaches to the enhancement of athletic performance through proprioceptive training might focus on improving the proprioception of the foot, (through, for example, a better use of the force exchanged with the ground), to improve running economy in runners or race walking in walkers, the push off with the foot in divers or the pedal stroke in cyclists. It would be useful, for example, to evaluate the effect of proprioceptive exercises, such as barefoot proprioceptive podalic gaits, the mobility toes, or the shifting of the load on the different support areas of the foot, or even better, to evaluate various combined proprioceptive exercises with different support surfaces. All of these exercises are designed to enhance the development of good automatic control by the central nervous system, and consequently a hypothetical improvement in sports performance.

In conclusion, in light of our current knowledge, future research should focus on analysing and deepening our understanding of proprioceptive training from different perspectives. Hence, we should move beyond many of the proprioceptive exercises described in the literature, which are performed on unstable surfaces, and which, as we have observed, often negatively affect athletic performance.

\section{REFERENCES}

Anderson, K.G., \& Behm, D.G. (2004). Maintenance of EMG activity and loss of force output with instability. The Journal of Strength \& Conditional Research, (18), 637-640. https://doi.org/10.1519/00124278-200408000-00043

Anderson, K.G., \& Behm, D.G. (2005). Trunk muscle activity increases with unstable squat movements. Canadian Journal of Applied Physiology, (30), 33-45. https://doi.org/10.1139/h05-103 
Ashton-Miller, J.A., Wojtys, E.M., Huston, L.J., \& Fry-Welch, D. (2001). Can proprioception really be improved by exercises? Clinical Orthopaedics and Related Research, 9(3), 128-136. https://doi.org/10.1007/s001670100208

Behm, D.G., Anderson, K., \& Currnew, R.S. (2002). Muscle force and activation under stable and unstable conditions. The Journal of Stregth \& Conditional Research, (16), 416-422. https://doi.org/10.1519/00124278-200208000-00012

Behm, D.G., Leonard, A., Young, W., Bonsey, A., \& Mackinnon, S. (2003). Trunk muscle EMG activity with unstable and unilateral exercises. Canadian Journal of Applied Physiology, (28)30, 326-341.

Behm, D.G., A.M Leonard, W.B. Young, W.A. Bonsey, \& Mackinnon, S.N. (2005). Trunk muscle electromyographic activity with unstable and unilateral exercises. The Journal of Strength \& Conditional Research, (19), 193-201. https://doi.org/10.1519/00124278-200502000-00033

Brooks, D., \& Brooks, C.C. (2002). BOSU Integrated Balance Training Manual. DW Fitness, LLC.

Bruhn, S., Kullmann, N., \& Gollhofer, A. (2004). The effects of a sensorimotor training and strength training on postural stabilisation, maximum isometric contraction and jump performance. International Journal of Sports Medicine, 25(1), 56-60. https://doi.org/10.1055/s-2003-45228

Cometti, G. (2002). El entrenamiento de la velocidad. Barcelona: Editorial Paidotribo.

Cosio-Lima, L.M., Reynolds, K.L., Winter, C., Paolone, V., \& Jones, M.T. (2003). Effects of Physioball and Conventional Floor Exercises on Early Phase Adaptations in Back and Abdominal Core Stability and Balance in Women. The Journal of Strength \& Conditional Research, 17(4), 721-725. https://doi.org/10.1519/00124278-200311000-00016

Cressey, E. M., West, C. A., Tiberio, D. P., Kraemer, W. J., \& Maresh, C. M. (2007). The effects of ten weeks of lower-body unstable surface training on markers of athletic performance. The Journal of Strength \& Conditioning Research, 21(2), 561-567. https://doi.org/10.1519/00124278-20070500000047

Dobrijevic, S., Moskovljevic, L., \& Dabovic, M. (2016). The influence of proprioceptive training on young rhythmic gymnasts balance. Facta Universitatis, Series: Physical Education and Sport, 247-255.

Eric, E., \& Rosenbaum, D. (2001). A multi-station proprioceptive exercise program in patients with ankle instability. Medicine \& Science in Sports \& Exercise, 33(12), 1991-1998. https://doi.org/10.1097/00005768-200112000-00003

Fitzpatrick, R., \& McCloskey, D.I. (1994). Proprioceptive, visual and vestibular thresholds for the perception of sway during standing in humans. The Journal of Physiology, (478), 173-186. https://doi.org/10.1113/iphysiol.1994.sp020240

Ganong, W. (2004). Fisiología médica. México: Editorial El manual moderno.

Gaurav, S., Pooja, A., Shishir, N., \& Tanvi, A. (2013). Comparative Analysis of Effectiveness of Conventional Proprioceptive Training and Multistation Proprioceptive Training on Vertical Jump Performance in Indian Basketball Players. Journal of Exercise Science and Physiotherapy, Vol. 9, No. 2: 97-104.

Gioftsidou, A., Malliou, P., Pafis, G., Beneka, A., Godolias, G., \& Maganaris, C. N. (2006). The effects of soccer training and timing of balance training on balance ability. European Journal of Applied Physiology, 96(6), 659-664. https://doi.org/10.1007/s00421-005-0123-3

Gomboş, L., Costeliana, L., \& Pop, I. (2016). The Proprioceptive Training in the Preparation of Handball Players. elSSN: 2357-1330. https://doi.org/10.15405/epsbs.2016.09.53

González, G., Oyarzo, C., Ficsher, M., De La Fuente, M.J., Diaz, V., \& Berral, F.J. (2011). Entrenamiento específico del balance postural en jugadores juveniles de fútbol. Revista Internacional de Medicina y Ciencias de la Actividad Física y el Deporte, 10(41), 95-114. 
Granacher, U., Gollhofer, A., \& Kriemler, S. (2010). Effects of balance training on postural sway, leg extensor strength, and jumping height in adolescents. Research quarterly for exercise and sport, 81(3), 245-251. https://doi.org/10.1080/02701367.2010.10599672

Gruber, M., \& Gollhofer, A. (2004). Impact of sensorimotor training on the rate of force development and neural activation. European Journal of Applied Physiology, (92), 98-105. https://doi.org/10.1007/s00421-004-1080-y

Han, J. (2014). Sport Attainment and Proprioception. International Journal of Sports Science \& Coaching Vol. 9, n 1:159-170. https://doi.org/10.1260/1747-9541.9.1.159

Han, J. (2015). Level of competitive success achieved by elite athletes and multi-joint proprioceptive ability. Journal of Science and Medicine in Sport, (18), 77-81. https://doi.org/10.1016/i.jsams.2013.11.013

Heitkamp, H.C., Horstmann, T., Mayer, F., Weller, J., \& Dickhuth, H.H. (2001). Gain in strength and muscular balance after balance training. International Journal of Sports Medicine, 22(4), 285-290. https://doi.org/10.1055/s-2001-13819

Hoffman, M., \& Payne, V.G. (1995). The effects of proprioceptive ankle disk training on healthy subjects. Journal of Orthopaedic \& Sports Physical therapy, 21(2), 90-93. https://doi.org/10.2519/jospt.1995.21.2.90

Komi, P.V. (2003). Stretch-shortening cycle. In: Strength and Power in Sport (2nd ed.). P.V. Komi, ed. Oxford: Blackwell, pp. 184-202. https://doi.org/10.1002/9780470757215.ch10

Kornecki, S., \& Zschorlich, V. (1994). The nature of the stabilizing functions of skeletal muscles. J. Biomech., (27), 215-225. https://doi.org/10.1016/0021-9290(94)90211-9

Kovacs, E.J., Birmingham, T.B., Forwell, L., \& Litchfield, R.B. (2004). Effect of training on postural control in figure skaters: a randomized controlled trial of neuromuscular versus basic off-ice training programs. Clinical Journal of Sports Medicine, 14(4), 215-224. https://doi.org/10.1097/00042752$200407000-00004$

Laudner, K.G., \& Koschnitzky, M.M. (2010). Ankle muscle activation when using the Both Side Utilized (BOSU) balance trainer. The Journal of Strength \& Conditional Research, 24(1), 218-222. https://doi.org/10.1519/JSC.0b013e3181c490d4

Lees, A., Vanrenterghem, J., \& De Clercq, D. (2004). The maximal and submaximal vertical jump: implications for strength and conditioning. The Journal of Strength \& Conditioning Research, 18(4), 787-791. https://doi.org/10.1519/00124278-200411000-00018

Lin, D.H., Lin, Y.F., Chai, H.M., Han, Y.C., \& Jan, M.H. (2007). Comparison of proprioceptive functions between computerized proprioception facilitation exercise and closed kinetic chain exercise in patients with knee osteoarthritis. Clinical Rheumatology, (26), 520-528. https://doi.org/10.1007/s10067-006-0324-0

Lloyd, D.G. (2001). Rationale for training programs to reduce anterior cruciate ligament injuries in Australian football. Journal of Orthopaedic and Sports Physical Therapy, 31(11), 645-654. https://doi.org/10.2519/jospt.2001.31.11.645

Marshall, P., \& Murphy, B. (2005). Core stability exercises on and off a Swiss Ball. Archives of Physical Medicine and Rehabilitation, 86(2), 242-249. https://doi.org/10.1016/i.apmr.2004.05.004

Marshall, P., \& Murphy, B. (2006). Changes in muscle activity and perceived exertion during exercises performed on a swiss ball. Applied Physiology, Nutrition and Metabolism, (31), 376-383. https://doi.org/10.1139/h06-006

Romero-Franco, N., Martínez-López, E., Lomas- Vega, R., Hita-Contreras, F., \& Martínez- Amat, A. (2012). Effects of proprioceptive training program on core stability and center of gravity control in sprinters. The Journal of Strength \& Conditioning Research, 26(8), 2071-2077. https://doi.org/10.1519/JSC.0b013e31823b06e6 
Ruiz, R., \& Richardson, M.T. (2005). Functional balance training using a domed device. Strength Cond. J., (27), 50-55. https://doi.org/10.1519/00126548-200502000-00010

Sevreza, V., \& Bourdin, C. (2015). On the Role of Proprioception in Making Free Throws in Basketball. Research Quarterly for Exercise and Sport, 86(3), 1-7. https://doi.org/10.1080/02701367.2015.1012578

Šimek, S., Milanovic, D., \& Jukic, I. (2008). The effects of proprioceptive training on jumping and agility performance. Kineziologija, 39(2), 131-141.

Sjölander, P., \& Johansson, H. (1997). Sensory endings in ligaments: response properties and effects on proprioception and motor control. In: Yahia L(ed) Ligaments and ligamentoplastics. Springer, Berlin Heidelberg New York, pp 39-83. https://doi.org/10.1007/978-3-642-60428-7 3

Tropp, H., \& Askling, C. (1988). Effects of ankle disc training on muscular strength and postural control. Clinical Biomechanics, (3), 88-91. https://doi.org/10.1016/0268-0033(88)90050-2

Westin, S.D., Hermeto, A., \& Noyes, F.R. (2015). A Six-Week Neuromuscular and Performance Training Program Improves Speed, Agility, Dynamic Balance, and Core Endurance in Junior Tennis Players. J Athl Enhancement, 4(1), 1-8. https://doi.org/10.4172/2324-9080.1000185

Willadson, J.M. (2004). The effectiveness of resistance exercises performed on unstable equipment. Strength Cond. J., (26), 70-74. https://doi.org/10.1519/00126548-200410000-00015

Yaggie, J. A., \& Campbell, B. M. (2006). Effects of balance training on selected skills. The Journal of Strength \& Conditioning Research, 20(2), 422-428. https://doi.org/10.1519/00124278-20060500000031

Yasuda, T., Nakagawa, T., Inoue, H., \& Iwamoto, M. (1999). The role of labyrinth, proprioception and plantar mechanosensors in the maintenance of an upright posture. European Archives of Oto-RhinoLaryngology, (256), 27-32. https://doi.org/10.1007/PL00014149

Ya-Wen Liu, Shiow-Chyn Jeng, \& Alex J. Y. Lee (2005). The influence of ankle sprains on proprioception. J. Exerc. Sci. Fit., 3(1), 33-38.

Ziegler, L.P., Gibson, M.H., \& McBride, J.M. (2002). Proprioceptive training improves vertical jump performance in untrained woman. Proceedings of the NSCA conference, (pp. 10-13). Las Vegas (USA).

\section{(C) $(1) \Theta$}

This work is licensed under a Attribution-NonCommercial-NoDerivatives 4.0 International (CC BY-NC-ND 4.0). 